\title{
Dietary cholesterol reduces lipoprotein lipase activity in the atherosclerosis-susceptible Bio $F_{1} B$ hamster
}

\author{
Martina A. McAteer ${ }^{1}$, David C. Grimsditch ${ }^{2}$, Martin Vidgeon-Hart ${ }^{3}$, \\ G. Martin Benson ${ }^{2}$ and Andrew M. Salter ${ }^{1} *$ \\ ${ }^{1}$ Division of Nutritional Biochemistry, School of Biosciences, University of Nottingham, \\ Sutton Bonington Campus, Loughborough, Leicestershire LE12 5RD, UK \\ ${ }^{2}$ Atherosclerosis Department, GlaxoSmithKline Pharmaceuticals, Harlow, Essex CM19 5AW, UK \\ ${ }^{3}$ Safety Assessment Department, GlaxoSmithKline Pharmaceuticals, Welwyn, Hertfordshire AL6 9AR, UK
}

(Received 8 April 2002 - Revised 14 October 2002 - Accepted 31 October 2002)

\begin{abstract}
We have compared lipoprotein metabolism in, and susceptibility to atherosclerosis of, two strains of male Golden Syrian hamster, the Bio $\mathrm{F}_{1} \mathrm{~B}$ hybrid and the dominant spot normal inbred (DSNI) strain. When fed a normal low-fat diet containing approximately $40 \mathrm{~g}$ fat and $0 \cdot 3 \mathrm{~g}$ cholesterol $/ \mathrm{kg}$, triacylglycerol-rich lipoprotein (chylomicron + VLDL) and HDL-cholesterol were significantly higher $(P<0.001)$ in Bio $\mathrm{F}_{1} \mathrm{~B}$ hamsters than DSNI hamsters. When this diet was supplemented with $150 \mathrm{~g}$ coconut oil and either 0.5 or $5.0 \mathrm{~g}$ cholesterol $/ \mathrm{kg}$, significant differences were seen in response. In particular, the high-cholesterol diet produced significantly greater increases in plasma cholesterol and triacylglycerol in the Bio $\mathrm{F}_{1} \mathrm{~B}$ compared with the DSNI animals $(P=0.002$ and $P<0.001$ for cholesterol and triacylglycerol, respectively). This was particularly dramatic in non-fasting animals, suggesting an accumulation of chylomicrons. In a second experiment, animals were fed $150 \mathrm{~g}$ coconut oil $/ \mathrm{kg}$ and $5.0 \mathrm{~g}$ cholesterol $/ \mathrm{kg}$ for 6 and 12 months. Again, the Bio $F_{1} B$ animals showed dramatic increases in plasma cholesterol and triacylglycerol, and this was confirmed as primarily due to a rise in chylomicron concentration. Post-heparin lipoprotein lipase activity was significantly reduced $(P<0.001)$ in the Bio $\mathrm{F}_{1} \mathrm{~B}$ compared with the DSNI animals at 6 months, and virtually absent at 12 months. Bio $\mathrm{F}_{1} \mathrm{~B}$ animals were also shown to develop significantly more $(P<0 \cdot 001)$ atherosclerosis. These results indicate that, in the Bio $\mathrm{F}_{1} \mathrm{~B}$ hybrid hamster, cholesterol feeding reduces lipoprotein lipase activity, thereby causing the accumulation of chylomicrons that may be associated with their increased susceptibility to atherosclerosis.
\end{abstract}

Lipoprotein lipase: Hepatic lipase: Dominant spot normal inbred strain: Bio $F_{1} B$ : Dietary cholesterol: Atherosclerosis: Hamster

The male Golden Syrian hamster has been used extensively in studies of lipoprotein metabolism because it is more similar in this respect to man than other rodent species. It has also proven to be a useful model in studying pharmacological (Kowala et al. 1991, 1993; Foxall et al. 1992; Otto et al. 1995; Nicolosi et al. 1998a; Pitman et al. 1998) and nutritional influences on the development of atherosclerosis (Parker et al. 1995; Kahlon et al. 1996; Nicolosi et al. 1997, 1998b,c; Xu et al. 1998; Mangiapane et al. 1999). Previous studies in our laboratory (Mangiapane et al. 1999) showed that one strain of hamster (dominant spot normal inbred, DSNI) required high levels of dietary cholesterol $(30 \mathrm{~g} / \mathrm{kg}$ diet $)$ to induce aortic lesions. This is in agreement with earlier findings of Nistor et al. (1987). However, the hybrid Bio $F_{1} B$ strain of hamster has been shown to develop aortic atherosclerosis at much lower dietary cholesterol concentrations (Kowala et al. 1991). The biochemical and physiological basis of this response to dietary cholesterol remains to be established.

The aim of the present study was to compare the lipoprotein responses of DSNI and Bio $\mathrm{F}_{1} \mathrm{~B}$ hamsters to dietary cholesterol. Plasma lipoprotein profiles and hepatic cholesterol concentrations of DSNI and Bio $\mathrm{F}_{1} \mathrm{~B}$ hamsters fed normal rodent diet or the same diet but supplemented with

\footnotetext{
Abbreviations: Apo, apolipoprotein; D, diet; DNSI, dominant spot normal inbred; F, fed or fasted; HFHC, high-fat, high-cholesterol diet; HFLC, high-fat, low-cholesterol diet; LPL, lipoprotein lipase; S, strain; T, length of time on diet; TAG, triacylglycerol.

* Corresponding author: Dr Andrew M. Salter, fax +44 115951 6122, email Andrew.Salter@nottingham.ac.uk
} 
$150 \mathrm{~g}$ coconut oil $/ \mathrm{kg}$ and either 0.5 or $5.0 \mathrm{~g}$ cholesterol $/ \mathrm{kg}$ were compared. In a further experiment, we investigated the effects of feeding $150 \mathrm{~g}$ coconut oil and $5.0 \mathrm{~g}$ cholesterol/kg for 6 and 12 months on lipoprotein concentrations, heparin-releasable plasma lipase activities and atherosclerosis in the two strains of hamster.

\section{Materials and methods}

\section{Animals and diets}

All procedures involving animals in these studies were subject to UK Home Office regulations

Study 1. Twenty-four 12-week-old DSNI hamsters (Joint Animal Breeding Unit, University of Nottingham, Nottingham, UK) and twenty-four 12-week-old Bio $F_{1} B$ hamsters (Biobreeders, Fitchburg, MA, USA) were housed individually at the University of Nottingham. Following acclimatisation, eight hamsters of each strain, selected by stratified randomisation of body weight, were fed normal RM3 diet containing approximately $40 \mathrm{~g}$ fat and $0.3 \mathrm{~g}$ cholesterol/kg (Special Diet Supplies, Chelmsford, Essex, UK) that had been ground to a powder. A further eight animals of each strain were fed the same diet supplemented with $150 \mathrm{~g}$ coconut oil (ICN Biomedicals Ltd, Thame, Oxon., UK) and $0.5 \mathrm{~g}$ cholesterol $/ \mathrm{kg}$ (high-fat, low-cholesterol diet; HFLC). The remaining eight animals per strain were fed RM3 diet supplemented with $150 \mathrm{~g}$ coconut oil and $5.0 \mathrm{~g}$ cholesterol $/ \mathrm{kg}$ (high-fat, high-cholesterol diet; HFHC). After 4 weeks, four hamsters from each group were fasted overnight, while the remaining animals were allowed free access to food until killing. The next morning, animals were anaesthetised with sodium pentabarbitone (Sagatal, $1 \mathrm{ml} / \mathrm{kg}$ ), and $3-4 \mathrm{ml}$ blood collected by cardiac puncture and placed into EDTA tubes. The liver was flushed with $10 \mathrm{ml}$ ice-cold $0.15 \mathrm{M}-\mathrm{NaCl}$, removed immediately, frozen in liquid $\mathrm{N}_{2}$ and stored at $-20^{\circ} \mathrm{C}$ awaiting analysis.

Study 2. Sixteen 12-week-old Bio $\mathrm{F}_{1} \mathrm{~B}$ and sixteen 12week-old DSNI male hamsters were housed at the University of Nottingham as described earlier. Following acclimatisation, they were fed RM3 diet (Special Diet Supplies) supplemented with $150 \mathrm{~g}$ coconut oil and $5.0 \mathrm{~g}$ cholesterol $/ \mathrm{kg}$. Animals from each strain were allocated to two groups of eight by stratified randomisation for body weight. One group from each strain was killed at 6 months and the remaining animals after 12 months. Animals were fed ad libitum until they were killed. At killing, four animals from each group were anaesthetised and blood collected as described earlier. The remaining animals were anaesthetised and injected with $200 \mu l$ heparin (Sigma, Poole, Dorset, UK) in $0.15 \mathrm{M}-\mathrm{NaCl}$ (approximately 7500 units/kg body weight) via the vena cava. After $5 \mathrm{~min}$, blood was collected from the heart by cardiac puncture and plasma separated and stored at $-20^{\circ} \mathrm{C}$ awaiting analysis for post-heparin lipase activity. The hearts and aortae were then removed and the aortae cut approximately $1 \mathrm{~mm}$ from the base of the heart. The aortae and hearts were then fixed in neutral-buffered formalin $(100 \mathrm{ml} / \mathrm{l})$ and stored at $4^{\circ} \mathrm{C}$ awaiting further analysis.

\section{Lipoprotein analysis}

In study 1, lipoprotein fractions were separated from plasma (normally $1 \mathrm{ml}$ ) by sequential ultracentrifugation and corrected for recovery (typically $>85 \%$ ) as previously described (Salter et al. 1998). VLDL, intermediate-density lipoproteins, LDL and HDL were separated within the density ranges $<1.006,1.006-1.020,1.020-1.060$ and $>1.060 \mathrm{~g} / \mathrm{ml}$ respectively. In non-fasted animals, the $<1.006 \mathrm{~g} / \mathrm{ml}$ fraction also contained chylomicrons and so has been termed the triacylglycerol (TAG)-rich lipoprotein fraction. In study 2, chylomicrons were first isolated from the plasma by spinning at $15500 \mathrm{~g}$ for $20 \mathrm{~min}$ at $12^{\circ} \mathrm{C}$. The remaining lipoproteins were then separated as described earlier. Cholesterol and TAG concentration in whole plasma and lipoprotein fractions were determined using diagnostic kits from Wako (Alpha Laboratories, Eastleigh, Hants., UK).

To confirm the identity of the TAG-rich lipoproteins, the apolipoprotein (Apo) B composition was examined by Western blotting. Lipoprotein fractions were delipidated (sample-ice-cold methanol-diethyl ether $(1: 12: 28$, by vol.)) and the remaining proteins subjected to SDSPAGE on $4-20 \%$ gradient gels. Separated proteins were then transferred on to nitrocellulose membrane by Western blotting. Blots were then incubated with human polyclonal antibody to ApoB (Calbiochem, Nottingham, UK) at a dilution of 1:10000. ApoB-48 and -100 were visualised using a secondary monoclonal anti-goat antibody conjugated to horseradish (Armoracia rusticana) peroxidase (1:5000 dilution) with enhanced chemiluminescence detection reagent (Amersham International, Amersham, Bucks., UK).

\section{Post-heparin lipase activity}

Lipoprotein lipase (LPL) and hepatic lipase activities were measured using the method of Corey \& Zilversmit (1977) as modified by Groot et al. (1992).

Samples were analysed in triplicate. Total lipase activity was measured in the presence of $0.15 \mathrm{M}-\mathrm{NaCl}$ while hepatic lipase activity was measured by inhibiting LPL with 3.55 $\mathrm{M}-\mathrm{NaCl}$. LPL was calculated as the difference between the two values. Activity was expressed as nmol fatty acid released/ml plasma per min.

\section{Hepatic free and esterified cholesterol}

Hepatic free and esterified cholesterol were separated by TLC, extracted and assayed enzymatically as described previously by Bennett et al. (1995).

\section{Measurement of atherosclerosis}

The heart was bisected beneath the atria and the base of the heart, which had approximately $1 \mathrm{~mm}$ of the ascending aorta protruding, and then submerged in optimum cutting temperature compound (Bayer Diagnostics, Leverkusen, Germany) for $24 \mathrm{~h}$ prior to sectioning. The heart was frozen on a cryostat chuck (Bright Instrument Company Ltd, Huntingdon, Cambs., UK) and $10 \mu \mathrm{m}$ sections of the 
aortic sinus were taken from where the three aortic valve leaflets first appeared (Paigen et al. 1987; Groot et al. 1996). Sections were stained with Oil Red O for neutral lipid and counterstained with Cole's haematoxylin for nuclei and basophilic tissue.

Images of the sections were acquired using an Olympus Zoom Stereo microscope (model SZCTV; Olympus Optical Co. Ltd, Southall, Middlesex, UK) and the area of Oil Red O lipid-staining in the sections was quantified using the Optimas Imaging software (version 5.2; Media Cybernetics Inc., Silver Spring, MD, USA) as previously described (Mangiapane et al. 1999). Ten alternate sections were examined and the average lesion area calculated.

In addition, the remaining portions of the fixed aortae were stained with Oil Red $\mathrm{O}$ and the stained areas from the aortic arch to the abdominal aorta were quantified as described previously (Mangiapane et al. 1999).

\section{Statistical analysis}

All data were checked for normal and equal distribution and those variables not normally distributed were converted to $\log$ values before statistical analyses. Such results are presented graphically as the geometric mean values and standard deviations. Data for animals fed on RM3 diet alone were analysed independently (two-way ANOVA) from that for the animals on the HFLC and HFHC diets. This was because the energy and nutrient density of the basic diet was considerably less than that of the high-fat diets. The remaining data from this trial (HFLC and HFHC groups) were analysed by three-way ANOVA, using the Genstat Computer Package (Lawes Agricultural Trust, Rothamstead, Herts., UK). The three factors in this analysis were defined as strain (S), diet (D) and whether the animals were fasted or fed (F). Significant $P$ values $(<0.05)$ for the effect of these factors or the interactions between them are shown in the tables. For the second trial, data was analysed by two-way ANOVA with $\mathrm{S}$ and length of time on the diet (T) as factors.

\section{Results}

DSNI hamsters had a significantly greater starting body weight than Bio $\mathrm{F}_{1} \mathrm{~B}$ hamsters (145.9 (SD 12.16) v. 124.5 (SD 15.73) g respectively, $P<0.001$ ). This weight difference increased during the course of the trial (final body weight 157.6 (SD 12.78) v. 124.3 (SD 15.78) g respectively, $P<0.001)$. However, no significant effects of $\mathrm{D}$ or $\mathrm{D} \times \mathrm{S}$ interaction were observed.

Table 1 shows the lipoprotein profiles of the two strains of hamsters fed the normal diet. Animals were killed either after an overnight fast or allowed constant access to food. Bio $F_{1} B$ hamsters had significantly higher plasma cholesterol concentrations than DSNI strain and this was significant in both the TAG-rich lipoprotein and HDL fractions $(P<0 \cdot 001)$. LDL-cholesterol did not differ between the two strains; intermediate-density cholesterol, although a very minor fraction, was significantly greater in the DSNI strain $(P=0 \cdot 001)$. Plasma cholesterol was greater in fed animals of both strains than those that were fasted overnight. Plasma total and
Table 1. Plasma lipoprotein concentrations ( $\mathrm{mm}$ ) in dominant spot normal inbred (DSNI) and Bio $\mathrm{F}_{1} \mathrm{~B}$ hamsters fed a normal diet ${ }^{\star}$ (Mean values and standard deviations for four hamsters per group)

\begin{tabular}{|c|c|c|c|c|c|c|}
\hline & & & \multirow[b]{2}{*}{ Mean } & \multirow[b]{2}{*}{ SD } & \multicolumn{2}{|c|}{$\begin{array}{c}\text { Statistical } \\
\text { significance of } \\
\text { effect (two-way } \\
\text { ANOVA) }\end{array}$} \\
\hline & & & & & Factor & $P \dagger$ \\
\hline \multirow[t]{3}{*}{ Total chol } & DSNI & $\begin{array}{l}\text { Fasted } \\
\text { Fed }\end{array}$ & $\begin{array}{l}1.83 \\
2.88\end{array}$ & $\begin{array}{l}0.16 \\
0.12\end{array}$ & S & $\begin{array}{r}<0.001 \\
0.003\end{array}$ \\
\hline & $F_{1} B$ & Fasted & $\begin{array}{l}2.00 \\
2.79\end{array}$ & 0.25 & & \\
\hline & & Fed & $3 \cdot 21$ & 0.16 & & \\
\hline \multirow[t]{4}{*}{ Total TAG } & DSNI & Fasted & $1 \cdot 10$ & 0.20 & & \\
\hline & & Fed & 1.13 & 0.32 & & \\
\hline & $F_{1} B$ & Fasted & 0.82 & 0.18 & & \\
\hline & & Fed & 1.33 & 0.43 & & \\
\hline \multirow[t]{4}{*}{ TRL-chol } & DSNI & Fasted & 0.34 & 0.14 & $S$ & $<0.001$ \\
\hline & & Fed & 0.25 & 0.10 & & \\
\hline & $\mathrm{F}_{1} \mathrm{~B}$ & Fasted & 0.88 & 0.21 & & \\
\hline & & Fed & 0.96 & 0.17 & & \\
\hline \multirow[t]{4}{*}{ TRL-TAG } & DSNI & Fasted & 0.91 & 0.34 & & \\
\hline & & Fed & 0.92 & 0.42 & & \\
\hline & $F_{1} B$ & Fasted & 0.79 & 0.14 & & \\
\hline & & Fed & 1.19 & 0.25 & & \\
\hline \multirow[t]{4}{*}{ IDL-chol } & DSNI & Fasted & 0.20 & 0.14 & $S$ & 0.002 \\
\hline & & Fed & 0.18 & 0.10 & & \\
\hline & $F_{1} B$ & Fasted & 0.02 & 0.01 & & \\
\hline & & Fed & 0.03 & 0.02 & & \\
\hline \multirow[t]{4}{*}{ LDL-chol } & DSNI & Fasted & 0.38 & 0.18 & & \\
\hline & & Fed & 0.74 & 0.45 & & \\
\hline & $F_{1} B$ & Fasted & 0.29 & 0.13 & & \\
\hline & & Fed & 0.44 & 0.05 & & \\
\hline \multirow[t]{4}{*}{ HDL-chol } & DSNI & Fasted & 0.91 & 0.10 & $S$ & $<0.001$ \\
\hline & & Fed & 0.91 & 0.29 & & \\
\hline & $\mathrm{F}_{1} \mathrm{~B}$ & Fasted & 1.60 & 0.21 & & \\
\hline & & Fed & 1.79 & 0.20 & & \\
\hline
\end{tabular}

chol, cholesterol; TAG, triacylglycerol; TRL, triacylglycerol-rich lipoprotein; IDL, intermediate-density lipoprotein; S, strain; F, fasted or fed.

* Hamsters were killed either after an overnight fast (fasted) or allowed constant access to food (fed); for details of diet and procedures, see p.342.

† $P$ values are shown for significant $(P<0.05)$ effects of $S$ and $F$. No significant interactions were seen between the two factors.

TAG-rich lipoprotein-TAG did not differ significantly between the strains. Plasma total TAG was reduced on fasting in Bio $F_{1} B$ animals, but not DSNI animals; however, the interaction between strain and fasting failed to reach statistical significance $(\mathrm{S} \times \mathrm{F}$ interaction, $P=0 \cdot 075)$.

Total plasma cholesterol concentrations were higher in animals fed HFHC diet for 4 weeks than in those fed the HFLC diet, with a greater increase seen in the Bio $F_{1} B$ animals $(\mathrm{D} \times \mathrm{S}$ interaction, $P=0.002$; Fig. 1). Fasting caused a marked decrease $(58 \%)$ in plasma cholesterol in $\mathrm{F}_{1} \mathrm{~B}$ compared with DSNI animals $(\mathrm{F} \times \mathrm{S}$ interaction, $P=0 \cdot 039)$. Fasting decreased plasma TAG in both strains, on both diets, but this was most pronounced on the HFHC diet where an $80 \%$ decrease was seen $(\mathrm{D} \times \mathrm{F}$ interaction, $P=0.002)$. Bio $\mathrm{F}_{1} \mathrm{~B}$ animals showed a significantly more pronounced increase in TAG in response to the HFHC diet $(\mathrm{S} \times \mathrm{D}$ interaction, $P<0 \cdot 001)$. The lipoproteins were analysed and the results for TAG-rich lipoproteins are shown in Fig. 2, whilst the results for the other lipoproteins are shown in Table 2. Fig. 2 indicates that most of the differences in total plasma lipids can be accounted for by changes in the TAG-rich lipoprotein fraction. 

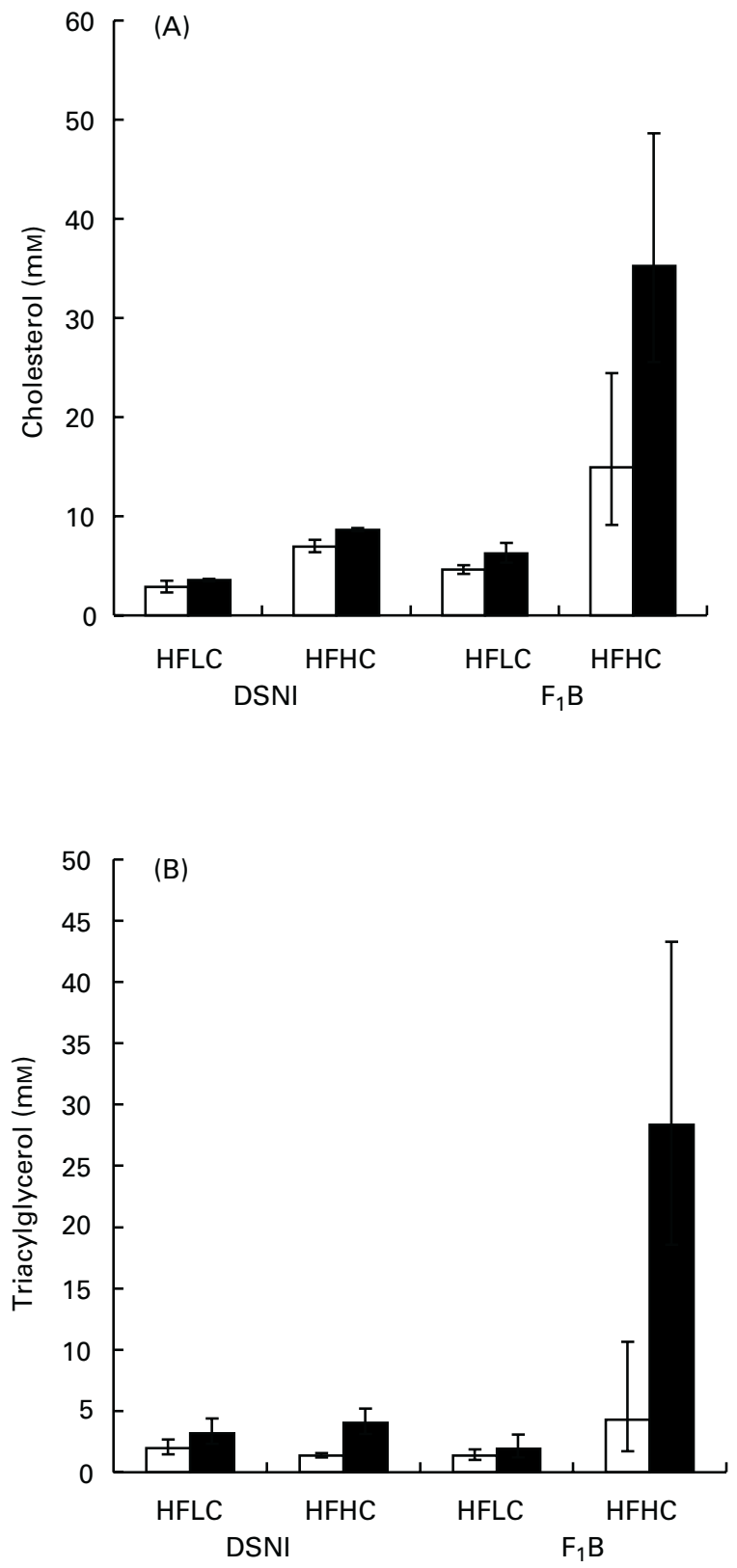

Fig. 1. Total plasma cholesterol (A) and triacylglycerol (B) concentrations in dominant spot normal inbred (DSNI) and Bio $\mathrm{F}_{1} \mathrm{~B}$ hamsters fed diets containing $150 \mathrm{~g}$ coconut oil $/ \mathrm{kg}$ and either $0.5 \mathrm{~g}$ (high-fat, low-cholesterol; HFLC) or $5.0 \mathrm{~g}$ (high-fat, high-cholesterol; HFHC) added cholesterol/kg for 4 weeks. Four animals from each group were allowed constant access to food up to time of killing (घ), while the remaining four were fasted overnight ( $\square$ ). Lipids were analysed as described on p. 342; for details of diets and procedures, see p. 342. Values are geometric means for eight animals with standard deviations shown by vertical bars.

The HFHC diet increased TAG-rich lipoprotein, TAG and cholesterol to a greater extent in Bio $\mathrm{F}_{1} \mathrm{~B}$ animals $(\mathrm{S} \times \mathrm{D}$ interaction, $P<0.001$ for both lipids). While fasting had little effect on TAG-rich lipoprotein lipids in animals on the HFLC diet, both were reduced in animals fed the HFHC diet $(\mathrm{D} \times \mathrm{F}$ interaction, $P=0.007$ and $P=0.002$ for cholesterol and TAG respectively).
(A)

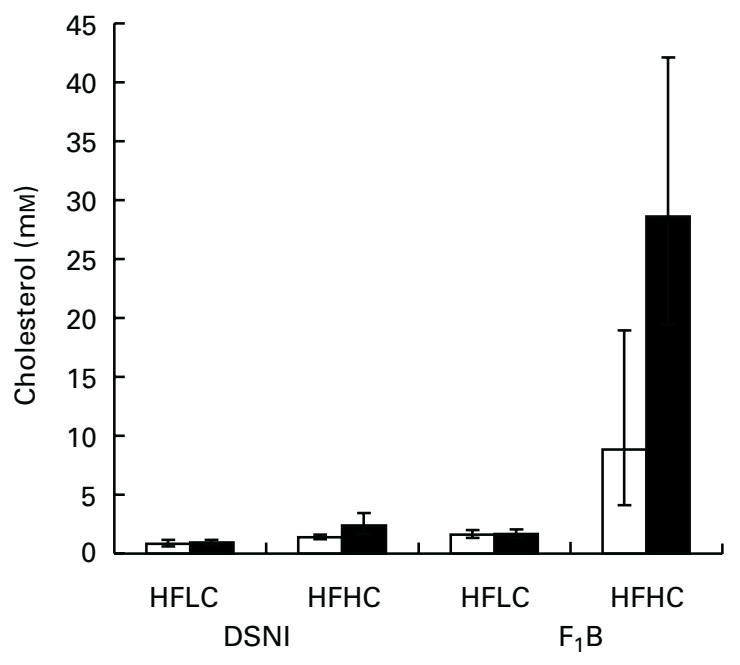

(B)

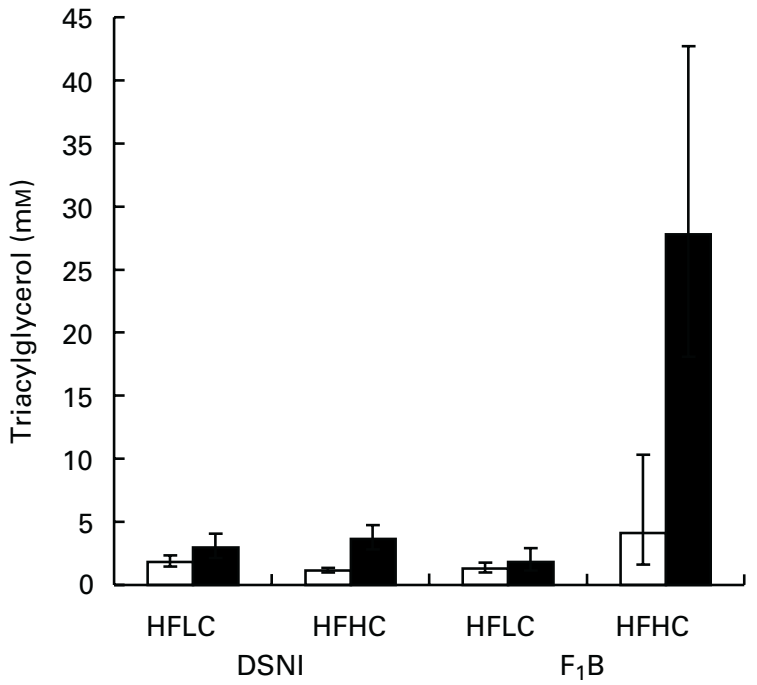

Fig. 2. Triacylglycerol-rich lipoprotein-cholesterol (A) and -triacylglycerol (B) concentrations in dominant spot normal inbred (DSNI) and Bio $F_{1} B$ hamsters fed diets containing $150 \mathrm{~g}$ coconut oil $/ \mathrm{kg}$ and either $0.5 \mathrm{~g}$ (high-fat, low-cholesterol; HFLC) or $5.0 \mathrm{~g}$ (high-fat, lowcholesterol; HFHC) added cholesterol/kg for 4 weeks. Four animals from each group were allowed constant access to food up to time of killing (घ), while the remaining four were fasted overnight $(\square)$. Lipids were analysed as described on p. 342; for details of diets and procedures, see p. 342 . Values are geometric means for eight animals with standard deviations shown by vertical bars.

Hamsters fed HFHC diet had a greater amount of cholesterol in intermediate-density lipoprotein compared with those fed HFLC diet (Table 2). This effect was more pronounced in $\mathrm{Bio} \mathrm{F}_{1} \mathrm{~B}$ animals as illustrated by a significant $\mathrm{S} \times \mathrm{D}$ interaction $(P<0 \cdot 001)$. Intermediate-density-lipoprotein cholesterol was reduced by fasting, but to a greater extent in animals fed the HFHC than in those fed HFLC diet $(\mathrm{D} \times \mathrm{F}$ interaction, $P=0 \cdot 002)$. LDL was higher in fed than fasted animals $(P=0.013)$ and DSNI animals had a 
Table 2. Intermediate-density lipoprotein (IDL)-, LDL- and HDL- cholesterol concentration $(\mathrm{mM})$ in dominant spot normal inbred (DSNI) and Bio $\mathrm{F}_{1} \mathrm{~B}$ hamsters after feeding diet supplemented with $150 \mathrm{~g}$ coconut oil and $5 \mathrm{~g}$ cholesterol $/ \mathrm{kg}$ (HFLC) or diet supplemented with $150 \mathrm{~g}$ coconut oil and $5 \mathrm{~g}$ cholesterol (HFHC)*

(Mean values and standard deviations for four hamsters per group)

\begin{tabular}{|c|c|c|c|c|c|c|c|c|}
\hline & & & \multicolumn{2}{|c|}{ HFLC } & \multicolumn{2}{|c|}{$\mathrm{HFHC}$} & \multicolumn{2}{|c|}{$\begin{array}{l}\text { Statistical signifi- } \\
\text { cance of effect } \\
\text { (three-way } \\
\text { ANOVA) }\end{array}$} \\
\hline & & & Mean & SD & Mean & SD & Factor & $P \dagger$ \\
\hline \multirow[t]{4}{*}{ IDL } & DSNI & Fasted & $0 \cdot 10$ & 0.04 & 0.63 & 0.30 & $S \times D$ & $<0.001$ \\
\hline & & Fed & 0.22 & 0.07 & 0.97 & 0.20 & $\mathrm{D} \times \mathrm{F}$ & 0.002 \\
\hline & $F_{1} B$ & Fasted & 0.04 & 0.01 & $1 \cdot 15$ & 0.14 & & \\
\hline & & Fed & 0.08 & 0.04 & 1.75 & 0.20 & & \\
\hline \multirow[t]{4}{*}{ LDL } & DSNI & Fasted & 0.55 & 0.31 & 3.39 & 0.21 & $\mathrm{~F}$ & 0.013 \\
\hline & & Fed & 1.24 & 0.33 & 3.52 & 0.79 & $S \times D$ & $<0.001$ \\
\hline & $F_{1} B$ & Fasted & 0.91 & 0.28 & $2 \cdot 34$ & 0.50 & & \\
\hline & & Fed & 1.92 & 0.47 & $2 \cdot 64$ & 1.05 & & \\
\hline \multirow[t]{4}{*}{ HDL } & DSNI & Fasted & 1.38 & 0.10 & 1.54 & 0.20 & $S \times D$ & 0.002 \\
\hline & & Fed & $1 \cdot 16$ & 0.26 & 1.67 & 0.72 & & \\
\hline & $\mathrm{F}_{1} \mathrm{~B}$ & Fasted & 2.05 & 0.13 & 1.74 & 0.27 & & \\
\hline & & Fed & 2.60 & 0.23 & 1.95 & 0.28 & & \\
\hline
\end{tabular}

\footnotetext{
S, strain; D diet; F, fasted or fed.

*Blood was collected following an overnight fast (fasted or following free access to food (fed)); for details of diets and procedures, see p. 342.

$\dagger P$ values are shown for significant $(P<0.05)$ effects of each variable on interactions between them.
}

greater increase in LDL-cholesterol in response to the higher dietary cholesterol level $(P<0 \cdot 001)$. HDL tended to rise in response to the high-cholesterol diet in DSNI animals, but fell in Bio $\mathrm{F}_{1} \mathrm{~B}$ animals, causing a significant $\mathrm{S} \times \mathrm{D}$ interaction for HDL-cholesterol $(P=0.002)$.

The livers of DSNI animals were significantly heavier than those from Bio $\mathrm{F}_{1} \mathrm{~B}$ animals $(P<0 \cdot 001$, Table 3$)$. However, this was not significant when expressed as \% body weight (results not shown). Livers from fed animals were heavier than those from fasted animals and the high-cholesterol diet also produced heavier livers. Hepatic free cholesterol (Table 3) was significantly higher in animals fed the HFHC diet $(P<0 \cdot 001)$ and was higher in fed than fasted animals $(P=0 \cdot 001)$. Interestingly, Bio F1B hamsters had a lower hepatic cholesteryl ester content than DSNI animals. Fasting did not influence hepatic cholesteryl ester, but levels increased significantly more in the DSNI than the Bio $\mathrm{F}_{1} \mathrm{~B}$ strain fed HFHC diet $(P=0 \cdot 002)$.

In the second study, animals were fed diets containing $150 \mathrm{~g}$ coconut oil and $5 \cdot 0 \mathrm{~g}$ cholesterol $/ \mathrm{kg}$ for 6 or 12 months.

Table 3. Liver weight, hepatic free cholesterol and cholesteryl ester concentrations in dominant spot normal inbred (DSNI) and Bio $\mathrm{F}_{1} \mathrm{~B}$ hamsters after feeding a normal diet supplemented with $150 \mathrm{~g}$ coconut oil and $0.5 \mathrm{~g}$ cholesterol $/ \mathrm{kg}$ (HFLC) or diet supplemented with $150 \mathrm{~g}$ coconut oil and $5 \mathrm{~g}$ cholesterol $/ \mathrm{kg}(\mathrm{HFHC})^{*}$ (Mean values and standard deviations for four hamsters per group)

\begin{tabular}{|c|c|c|c|c|c|c|c|c|}
\hline & & & \multicolumn{2}{|c|}{ HFLC } & \multicolumn{2}{|c|}{$\mathrm{HFHC}$} & \multicolumn{2}{|c|}{$\begin{array}{l}\text { Statistical signifi- } \\
\text { cance of effect } \\
\text { (three-way } \\
\text { ANOVA) }\end{array}$} \\
\hline & & & Mean & SD & Mean & SD & Factor & $P \dagger$ \\
\hline \multirow[t]{4}{*}{ Liver weight (g) } & DSNI & Fasted & 5.65 & 0.06 & $6 \cdot 80$ & 0.77 & S & $<0.001$ \\
\hline & & Fasted & 7.57 & 0.33 & $9 \cdot 18$ & 0.40 & D & $<0.001$ \\
\hline & F1B & Fasted & 4.75 & 0.79 & 5.53 & 0.96 & $\mathrm{~F}$ & $<0.001$ \\
\hline & & Fed & 5.73 & 0.92 & $7 \cdot 23$ & 0.73 & & \\
\hline \multirow[t]{4}{*}{ Cholesterol (mg/liver) } & DSNI & Fasted & 9 & 5 & 20 & 4 & D & $<0.001$ \\
\hline & & Fed & 12 & 2 & 23 & 4 & $\mathrm{~F}$ & 0.001 \\
\hline & $F_{1} B$ & Fasted & 9 & 2 & 118 & 3 & & \\
\hline & & Fed & 10 & 1 & 27 & 3 & & \\
\hline \multirow[t]{4}{*}{ Cholesteryl ester (mg/liver) } & DSNI & Fasted & 13 & 8 & 266 & 18 & $S \times D$ & 0.002 \\
\hline & & Fed & 9 & 3 & 264 & 102 & & \\
\hline & $F_{1} B$ & Fasted & 10 & 3 & 131 & 11 & & \\
\hline & & Fed & 9 & 2 & 189 & 56 & & \\
\hline
\end{tabular}

S, strain; D, diet; F, fed or fasted.

* Livers were removed following an overnight fast (fasted) or following free access to food (fed); for details of diets and procedures, see p. 342.

$\dagger P$ Values are shown for significant $(P<0.05)$ effects of each variable or interactions between them. 
As with the first trial, Bio $\mathrm{F}_{1} \mathrm{~B}$ animals were smaller than DSNI animals at equivalent ages. The diet was generally well tolerated by both strains, although the Bio $F_{1} B$ animals tended to gain more weight, and this was significant by 12 months (25.0 (SD 2.7) v. 13.5 (SD 8.3) g body-weight gain, $P=0.002$ ).

The chylomicron results are shown in Fig. 3 and the results for the other lipoproteins are shown in Table 4. Chylomicron-cholesterol and -TAG were much higher in Bio $F_{1} B$ than DSNI animals and rose more dramatically between the two time points in the Bio $F_{1} B$ animals (T $\times \mathrm{S}$ interaction, $P=0.002$ and $P=0.001$ respectively, Fig. 3). The identity of this fraction as chylomicrons was confirmed by Western blotting using a polyclonal antibody against human ApoB, which indicated that virtually all of the ApoB was of the ApoB-48 rather than -100 isoform (results not shown).

Similar increases in VLDL-cholesterol $(P=0 \cdot 005)$ and -TAG $(P=0.002)$ were also seen with time in Bio $\mathrm{F}_{1} \mathrm{~B}$ hamsters (Table 4). However, this fraction contained both ApoB-38 and -100 (results not shown) and was likely to be contaminated with chylomicrons. Intermediate-density-lipoprotein cholesterol was higher in Bio $F_{1} B$ than DSNI animals but tended to decrease with time. By contrast, LDL-cholesterol did not change significantly with time and did not differ between strains. Although both strains had similar levels of HDL-cholesterol after 6 months, they tended to rise between 6 and 12 months in DSNI hamsters and fall in Bio $\mathrm{F}_{1} \mathrm{~B}$ hamsters causing a significant $\mathrm{S} \times \mathrm{T}$ interaction $(P=0 \cdot 012)$.

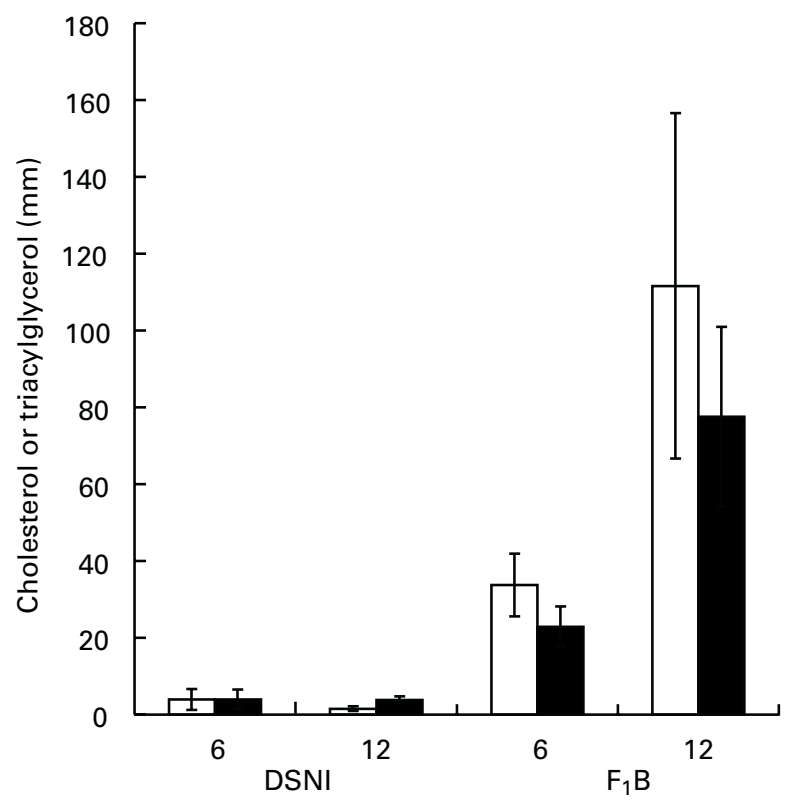

Time (months)

Fig. 3. Total chylomicron-cholesterol ( $\square$ ) and -triacylglycerol ( $\square$ ) concentrations in dominant spot normal inbred (DSNI) and Bio $F_{1} B$ hamsters fed diets containing $150 \mathrm{~g}$ coconut oil $/ \mathrm{kg}$ and $5.0 \mathrm{~g}$ added cholesterol/kg for 6 or 12 months. Animals were allowed constant access to food until time of killing. Chylomicrons were isolated and lipids analysed as outlined on p. 342; for details of diets and procedures, see p. 342. Values are geometric means for four animals with standard deviations shown by vertical bars.
LPL was higher in DSNI animals than Bio $\mathrm{F}_{1} \mathrm{~B}$ $(P<0.001$, Fig. 4) and was significantly reduced with time in both strains $(P=0 \cdot 006)$. As a result, activity was negligible in the Bio $F_{1} B$ animals after 12 months of feeding. Hepatic lipase tended to increase with time in DSNI animals, but not Bio $\mathrm{F}_{1} \mathrm{~B}$ animals $(\mathrm{S} \times \mathrm{T}$ interaction, $P=0 \cdot 017)$.

Atherosclerosis was determined in both the aortic sinus and, by en face staining, throughout the length of the aorta (Fig. 5). No significant difference could be seen in staining in the aortic sinus between the two strains at 6 months. However, by 12 months much more staining was seen in the aortic sinus of the Bio $\mathrm{F}_{1} \mathrm{~B}$ animals $(\mathrm{S} \times \mathrm{T}$ interaction, $P=0.001)$. In the rest of the aorta, Bio $\mathrm{F}_{1} \mathrm{~B}$ animals showed significantly more atherosclerosis at both time points $(P<0 \cdot 001)$, with the amount of staining increasing with time $(P<0.001)$. Lesions were generally restricted to the inner curvature of the aortic arch. By 12 months, atherosclerosis had spread to both the thoracic and abdominal aorta in the Bio $\mathrm{F}_{1} \mathrm{~B}$, although this was not seen in the DSNI hamsters.

\section{Discussion}

Previous work has indicated that the Bio $F_{1} B$ hybrid hamster is more susceptible to atherosclerosis than other non-hybrid strains (Kowala et al. 1991). The aim of the present studies was to compare the lipoprotein response of Bio $\mathrm{F}_{1} \mathrm{~B}$ hamster to dietary saturated fat and cholesterol with that of the more atherosclerosis-resistant DSNI strain of hamster.

Initially, we compared the lipoprotein profile of the two strains fed a normal diet with no added cholesterol or fat. No dramatic differences between the two strains were seen, although TAG-rich lipoproteins and HDL-cholesterol were both found to be higher in the Bio $\mathrm{F}_{1} \mathrm{~B}$ than the DSNI strain. HDL was the predominant cholesterol-carrying lipoprotein in both strains, which confirms our previous findings (Sessions \& Salter, 1994) and those of other investigators (Trautwein et al. 1993).

The addition of fat and cholesterol to the diet, particularly at the higher level of $5.0 \mathrm{~g}$ cholesterol $/ \mathrm{kg}$, elicited different responses in the two strains. Bio $F_{1} B$ animals responded with a marked increase in TAG-rich lipoprotein-cholesterol and -TAG, which was most pronounced in animals on the high-cholesterol diet and in the fed state. We have previously shown an increase in VLDL-cholesterol and -TAG in other strains of hamster in response to dietary cholesterol (Sessions et al. 1994; Billett et al. 2000). However, the magnitude of the changes seen in the Bio $\mathrm{F}_{1} \mathrm{~B}$ hamsters was considerably greater than in other strains. The response seen in the present study is also considerably greater than that found by Trautwein et al. (1993), who compared the response to 4.0 or $8.0 \mathrm{~g}$ cholesterol/kg in Bio $\mathrm{F}_{1} \mathrm{~B}$ hamsters with that of two other strains However, these workers used a purified diet containing significantly less saturated fat $(50 \mathrm{~g}$ butter $/ \mathrm{kg}$ ) than was used in the present study.

Elevated concentrations of TAG-rich lipoprotein, particularly in the fed state, and reduced hepatic cholesteryl ester storage in the Bio $F_{1} B$ animals is consistent with 
Table 4. Lipoprotein cholesterol concentration in dominant spot normal inbred (DSNI) and Bio $F_{1} B$ hamsters fed $150 \mathrm{~g}$ coconut oil and $5 \mathrm{~g}$ cholesterol $/ \mathrm{kg}$ for 6 or 12 months*

(Mean values and standard deviations for four animals per group)

\begin{tabular}{|c|c|c|c|c|c|c|c|}
\hline & & \multicolumn{6}{|c|}{ Time (months) } \\
\hline & & \multicolumn{2}{|c|}{6} & \multicolumn{2}{|c|}{12} & \multicolumn{2}{|c|}{$\begin{array}{l}\text { Statistical significance of } \\
\text { effect (two-way ANOVA) }\end{array}$} \\
\hline & & Mean & SD & Mean & SD & Factor & $P \dagger$ \\
\hline \multirow[t]{2}{*}{ VLDL-TAG } & DSNI & 2.63 & 0.98 & 1.78 & 0.44 & $\mathrm{~S} \times \mathrm{T}$ & 0.002 \\
\hline & $F_{1} B$ & 10.01 & 2.51 & 21.44 & 5.56 & & \\
\hline \multirow[t]{2}{*}{ VLDL-chol } & DSNI & $2 \cdot 60$ & 0.58 & 1.90 & 0.76 & $S \times T$ & 0.005 \\
\hline & $\mathrm{F}_{1} \mathrm{~B}$ & $10 \cdot 64$ & 1.55 & 22.87 & 7.27 & & \\
\hline \multirow[t]{2}{*}{ IDL-chol } & DSNI & $2 \cdot 20$ & 0.37 & $1 \cdot 18$ & 0.61 & $S$ & 0.028 \\
\hline & $\mathrm{F}_{1} \mathrm{~B}$ & 2.63 & 0.35 & 1.88 & 0.40 & $\mathrm{~T}$ & 0.002 \\
\hline \multirow[t]{2}{*}{ LDL-chol } & DSNI & 3.89 & 0.85 & 4.39 & 0.94 & & \\
\hline & $F_{1} B$ & 3.49 & 0.29 & 3.53 & 0.86 & & \\
\hline \multirow[t]{2}{*}{ HDL-chol } & DSNI & $2 \cdot 27$ & 0.46 & 3.32 & 0.61 & $S \times T$ & 0.012 \\
\hline & $\mathrm{F}_{1} \mathrm{~B}$ & 1.96 & 0.24 & 1.80 & 0.20 & & \\
\hline
\end{tabular}

chol, cholesterol; IDL, intermediate-density lipoprotein; S, strain; T, length of time on the diet.

${ }^{*}$ At each time point, animals were bled by cardiac puncture following free access to food and plasma lipoproteins prepared; for details of diet and procedures, see p. 342.

$\dagger P$ Values are shown for significant $(P<0.05)$ effects of each variable or interactions between the variables.

a reduced activity of LPL on these lipoproteins, and hence a reduced production and clearance of cholesterol-rich remnants by the liver. To test this hypothesis, a further experiment was designed to determine the effect of the HFHC diet on post-heparin LPL activity. The present trial was also designed to compare the development of atherosclerotic lesions in the two strains over time.

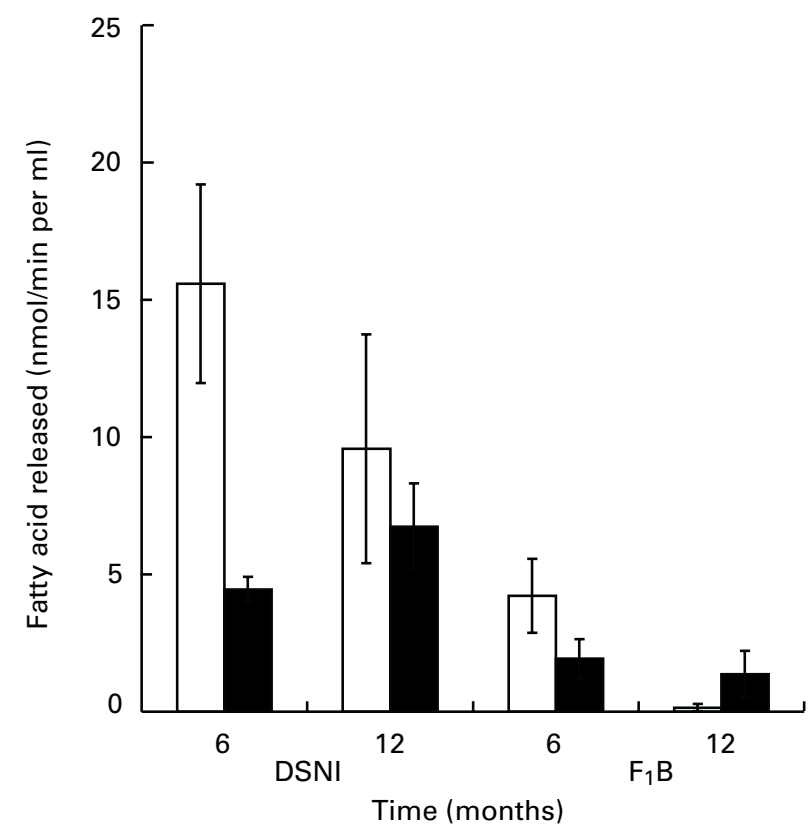

Fig. 4. Post-heparin lipoprotein lipase $(\square)$ and hepatic lipase ( $\square$ ) activities in dominant spot normal inbred (DSNI) and Bio $F_{1} B$ hamsters fed a diet containing $150 \mathrm{~g}$ coconut oil $/ \mathrm{kg}$ and $5.0 \mathrm{~g}$ added cholesterol $/ \mathrm{kg}$ for 6 or 12 months. Animals were allowed constant access to food until time of killing. Animals were injected with heparin, blood collected and plasma lipase activity determined as described on p. 342; for details of diets and procedures, see p. 342. Values are geometric means for four animals with standard deviations shown by vertical bars.
After 6 months on a diet containing $150 \mathrm{~g}$ coconut oil and $5.0 \mathrm{~g}$ cholesterol $/ \mathrm{kg}$, Bio $\mathrm{F}_{1} \mathrm{~B}$ hamsters had much greater plasma total cholesterol and TAG concentrations than DSNI hamsters, and this was largely due to an accumulation of chylomicrons (as identified by density and presence of ApoB-48). By 12 months, chylomicron-TAG was more than 50-fold greater in the Bio $F_{1} B$ compared with the DSNI animals. This accumulation of chylomicrons was shown to be associated in Bio $F_{1} B$ animals with much lower activity of heparin-releasable LPL, which declined almost to zero by 12 months. Thus, the massive hyperlipidaemia associated with cholesterol feeding in Bio $\mathrm{F}_{1} \mathrm{~B}$ hamsters is associated with an accumulation of chylomicrons, and to a lesser extent VLDL, due to a reduction in LPL activity.

At the present time, we do not know why LPL responds so differently to dietary cholesterol in these two strains. Heparin releases LPL from the vascular endothelium of many tissues in the body, with adipose tissue and skeletal muscle being quantitatively the most important. In the fed state, due to the actions of insulin, LPL activity in adipose tissue would be expected to be up-regulated and thus make the greatest contribution to the released pool. However, the fact that by 12 months virtually no activity could be detected in Bio $F_{1} B$ hamsters suggested that all tissues of the body might be affected. Absence of functional LPL is one of the underlying causes of type 1 hyperlipoproteinaemia in man. Models of such hyperlipidaemia have been described in the cat (Ginziger et al. 1996) and mink (Savonen et al. 1999). However, these are a direct result of mutations within the gene resulting in a failure to produce functional LPL. The apparent deficiency of LPL activity in the Bio $F_{1} B$ animals was dependent on feeding dietary cholesterol. It is possible that cholesterol may exert direct effects on LPL gene expression. Sterol regulatory element binding proteins (Kim \& Spiegelman, 1996; Shimano et al. 1996, 1997; Yang \& Deeb, 1998) may regulate the transcription of the LPL gene. It has been shown that depletion of cholesterol, or over-expression of 

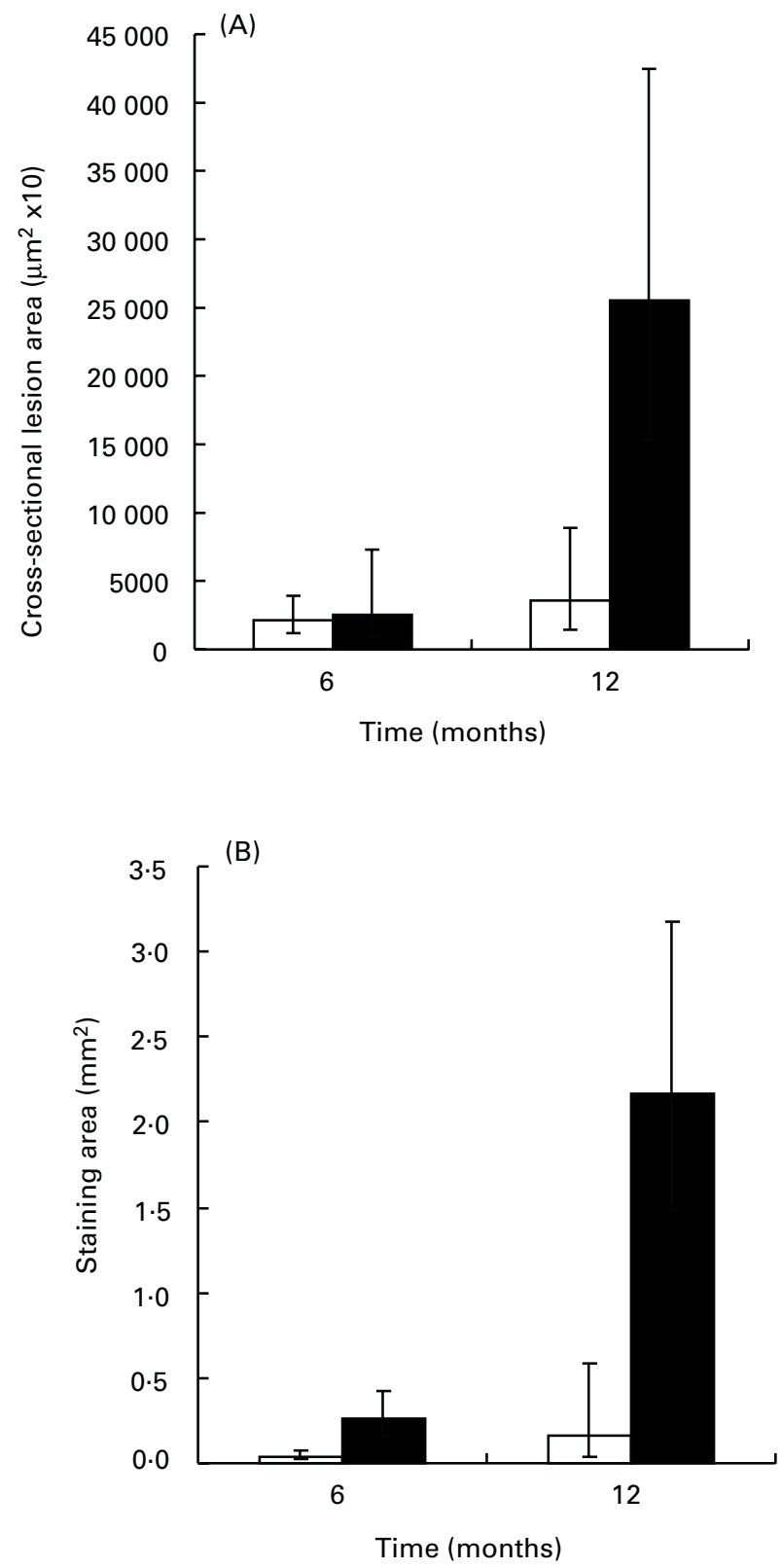

Fig. 5. Atherosclerosis in dominant spot normal inbred ( $\square$ ) and Bio $\mathrm{F}_{1} \mathrm{~B}(\boldsymbol{\square})$ hamsters fed a diet containing $150 \mathrm{~g}$ coconut oil $/ \mathrm{kg}$ and $5.0 \mathrm{~g}$ added cholesterol $/ \mathrm{kg}$ for 6 or 12 months. Atherosclerosis was quantified as Oil Red O-staining of either sections taken from the aortic sinus (A) or en face staining of the aorta from the aortic arch to the abdominal aorta (B) as described on p. 343; for details of diets and procedures, see p. 342. Values are geometric means for eight animals with standard deviations shown by vertical bars.

sterol regulatory element binding proteins 1 or 2 induces LPL gene expression in 3T3-L1 adipocytes (Schoonjans et al. 2000). It is interesting to speculate that polymorphisms in the sterol response element of the LPL promoter may influence the response of the two strains to dietary cholesterol. However, at present, the molecular basis of this strain-specific response to dietary cholesterol remains to be established.

It is also not clear whether this phenotype is restricted to the Bio $F_{1} B$ hybrid or may be associated with one of the parent strains. The Bio $\mathrm{F}_{1} \mathrm{~B}$ hybrid is derived from two highly inbred strains, namely Bio 87.20 female and Bio 1.5 male. Little is known about lipid metabolism in either of the parent strains, although there are some reports of altered cholesterol metabolism in the Bio 87.20 strain (Schaffer et al. 1981; Singhal et al. 1983). We are not aware, however, of any reports of the effect of cholesterol feeding on plasma TAG concentrations in the parent strains. It is understood that the Bio $\mathrm{F}_{1} \mathrm{~B}$ hybrid was originally favoured due to its relative longevity and general robustness (C. VanDongen, personal communication) prior to the discovery of an increased susceptibility to atherosclerosis (Kowala et al. 1991). Further investigation of the parental strains should provide useful information as to the genetic basis of the increased susceptibility to hyperlipidaemia.

In general, we confirm that Bio $\mathrm{F}_{1} \mathrm{~B}$ animals are more susceptible to atherosclerosis than DSNI animals. While at 6 months no significant difference was seen in the amount of lipid staining seen at the aortic sinus between the two strains of animal, significantly more staining was seen in the aortic arch of Bio $\mathrm{F}_{1} \mathrm{~B}$ animals $(P<0 \cdot 001)$. By 12 months, little change was seen in the amount of atherosclerosis in the DSNI animals, but lipid staining at the aortic sinus and throughout the rest of the aorta increased dramatically, and was 5-6-fold greater in the Bio $F_{1} B$ compared with the DSNI animals. Thus, the increased susceptibility of the Bio $\mathrm{F}_{1} \mathrm{~B}$ hamster to atherosclerosis became increasingly apparent the longer the animals were fed an atherogenic diet.

It remains to be established which lipoproteins are responsible for this increased susceptibility to atherosclerosis. It has generally been assumed that familial LPL deficiency is not associated with increased risk of atherosclerosis in man. However, Benlian et al. (1996) reported premature atherosclerosis in four patients suffering from this condition. Mice that are heterozygous for LPL deficiency actually show a decreased susceptibility to atherosclerosis (Semenkovich et al. 1998). Semenkovich et al. (1998) suggested that a deficiency of LPL in the vessel wall could prevent the retention of atherogenic lipoproteins. However, in the ApoE knockout mouse, over-expression of LPL appears to protect against atherosclerosis (Yaghu et al. 1999). Over-expression in these animals was found in a number of tissues including the aorta. In the cholesterol-fed Bio $\mathrm{F}_{1} \mathrm{~B}$ hamster, a deficiency in LPL activity was associated with an increased susceptibility to atherosclerosis. This could not be attributed to changes in LDL-cholesterol, which was not significantly different between the two strains. Compared with the heterozygous LPL-deficient mice (Semenkovich et al. 1998), plasma TAG and cholesterol levels were much greater in the Bio $\mathrm{F}_{1} \mathrm{~B}$ hamster. Feeding cholesterol to these animals resulted in the accumulation of cholesterol-enriched chylomicrons that may be atherogenic. Furthermore, we do not know the relative activity of LPL in different tissues. Recent evidence suggests that, in mice, cholesterol feeding actually induces LPL expression in macrophages, but not in adipose tissue or muscle (Zhang et al. 2001). This was shown to be mediated through the oxysterol liver $\mathrm{X}$ receptor class of transcription factors. Thus, the reduction 
in heparin-releasable LPL may not reflect a similar change in LPL activity within the artery wall. Further study of the cholesterol-fed Bio $\mathrm{F}_{1} \mathrm{~B}$ hamster should yield some useful insights into the possible role of TAG-rich lipoproteins and LPL in the development of atherosclerosis.

In conclusion, we confirm the susceptibility of Bio $F_{1} B$ hamsters to atherosclerosis at relatively modest dietary cholesterol concentrations. Prolonged consumption of an atherogenic diet results in the development of lesions throughout the aorta. This increase in susceptibility to the effects of dietary cholesterol is associated with a dramatic accumulation of chylomicrons in the plasma as a result of reduced LPL activity. The mechanisms underlying this strain difference remain to be established.

\section{Acknowledgements}

The authors would like to thank the late Ms Judi Simpson and $\mathrm{Mr}$ Richard Plant for their excellent technical assistance. M. A. M. was the recipient of a BBSRC Case studentship.

\section{References}

Benlian P, De Gennes JL, Foubert L, Zhang H, Gagne SE \& Hayden M (1996) Premature atherosclerosis in patients with familial chylomicronemia caused by mutations in the lipoprotein lipase gene. New England Journal of Medicine 335, $848-854$.

Bennett AJ, Billett MA, Salter AM, Mangiapane EH, Bruce JS, Anderton KL, Marenah CB, Lawson N \& White DA (1995) Modulation of hepatic apolipoprotein B, 3-hydroxy-3-methylglutaryl-CoA reductase and low density lipoprotein receptor mRNA and plasma lipoprotein concentrations by defined dietary fats. Biochemical Journal 311, 167-173.

Billett MA, Bruce JS, White DA, Bennett AJ \& Salter AM (2000) Interactive effects of dietary cholesterol and different saturated fatty acids on lipoprotein metabolism in the hamster. British Journal of Nutrition 84, 439-447.

Corey JE \& Zilversmit DB (1977) Validation of a stable emulsion for the assay of lipoprotein lipase activity. Journal of Laboratory Clinical Medicine 89, 666-674.

Foxall TL, Shwaery GT, Stucchi AF, Nicolosi RJ \& Wong SS (1992) Dose-related effects of doxazosin on plasma lipids and aortic fatty streak formation in the hypercholesterolemic hamster model. American Journal of Pathology 140, $1357-1363$.

Ginzinger DG, Lewis MES, Ma Y, Jones BR, Liu G, Jones SD \& Hayden MR (1996) A mutation in the lipoprotein lipase gene is the molecular basis of chylomicronemia in a colony of domestic cats. Journal of Clinical Investigation 97, $1257-1266$.

Groot PHE, Pearce NJ, Suckling KE \& Eisenberg S (1992) Effects of cholestyramine on lipoproteins levels and metabolism in Syrian hamsters. Biochimica et Biophysica Acta 1123, 76-84.

Groot PH, van Vlijmen BJ, Benson GM, Hofker MH, Schiffelers R, Vidgeon-Hart M \& Havekes LM (1996) Quantitative assessment of aortic atherosclerosis in APOE*3 Leiden transgenic mice and its relationship to serum cholesterol exposure. Arteriosclerosis, Thrombosis and Vascular Biology 16, 926-933.

Kahlon TS, Faye I, Chow MS, Delilah W, Irving BS \& Sayre RN (1996) Cholesterol response and foam cell formation in hamsters fed two levels of saturated fat and various levels of cholesterol. Nutrition Research 16, 1353-1368.

Kim JB \& Spiegelman BM (1996) ADD1/SREBP1 promotes adipocyte differentiation and gene expression linked to fatty acid metabolism. Genes and Development 10, 1096-1107.

Kowala MC, Mazzucco CE, Hartl KS, Seiler SM, Warr GA, Abid S \& Grove RI (1993) Prostacyclin agonists reduce early atherosclerosis in hyperlipidemic hamsters. Arteriosclerosis and Thrombosis 13, 435-444.

Kowala MC, Nunnari JJ, Durham SK \& Nicolosi RJ (1991) Doxazosin and cholestyramine similarly decrease fatty streak formation in the aortic arch of hyperlipidemic hamsters. Atherosclerosis 91, 35-49.

Mangiapane EH, McAteer MA, Benson GM, White DA \& Salter AM (1999) Modulation of the regression of atherosclerosis in the hamster by dietary lipids: comparison of coconut oil and olive oil. British Journal of Nutrition 82, 401-409.

Nicolosi RJ, Rogers EJ, Kritchevsky D, Scomeca JA \& Huth PJ (1997) Dietary conjugated linoleic acid reduces plasma lipoproteins and early atherosclerosis in hypercholesterolemic hamsters. Artery 22, 266-277.

Nicolosi RJ, Wilson TA \& Krausse BR (1998a) The ACAT inhibitor, CI-1011 is effective in the prevention and regression of aortic fatty streak area in hamsters. Atherosclerosis 137, $77-85$.

Nicolosi RJ, Wilson TA, Lawton C, Rogers EJ, Wiseman SA, Tijburg LBM \& Kritchevsky D (1998b) The greater atherogenicity of nonpurified diets versus semipurified diets in hamsters is mediated via differences in plasma cholesterol distribution, LDL oxidative susceptibility and plasma $\alpha$-tocopherol concentration. Journal of Nutritional Biochemistry 9, 591-597.

Nicolosi RJ, Wilson TA, Rogers EJ \& Kritchevsky D (1998c) Effects of specific fatty acids $(8: 0,14: 0$, cis-18:1, trans$18: 1)$ on plasma lipoproteins, early atherogenic potential, and LDL oxidative properties in the hamster. Journal of Lipid Research 39, 1972-1980.

Nistor A, Bulla A, Filip DA \& Radu A (1987) The hyperlipidemic hamster as a model of experimental atherosclerosis. Atherosclerosis $\mathbf{6 8}, 159-173$.

Otto J, Ordovas JM, Smith D, van Dongen D, Nicolosi RJ \& Schaefer EJ (1995) Lovastatin inhibits diet induced atherosclerosis in F1B Golden Syrian hamsters. Atherosclerosis 114, 19-28.

Paigen B, Morrow A, Holmes PA, Mitchell D \& Williams RA (1987) Quantitative assessment of atherosclerotic lesions in mice. Atherosclerosis $\mathbf{6 8}, 231-240$.

Parker RA, Sabrah T, Cap M \& Gill BT (1995) Relation of vascular oxidative stress, $\alpha$-tocopherol, and hypercholesterolemia to early atherosclerosis in hamsters. Arteriosclerosis, Thrombosis and Vascular Biology 15, 349-358.

Pitman WA, Osgood DP, Smith D, Schaefer EJ \& Ordovas JM (1998) The effect of diet and lovastatin on regression of fatty streak lesions and on hepatic and intestinal mRNA levels for LDL receptor and HMG CoA reductase in F1B hamsters. Atherosclerosis 138, 43-52.

Salter AM, Mangiapane EH, Bennett AJ, Bruce JS, Billett MA, Anderton KL, Marenah CB, Lawson N \& White DA (1998) The effect of different dietary fatty acids on lipoprotein metabolism: concentration-dependent effects of diets enriched in oleic, myristic, palmitic and stearic acids. British Journal of Nutrition 79, 195-202.

Savonen R, Nordstoga K, Christophersen B, Lindberg A, Shen Y, Hultin M, Olivecrona T \& Olivecrona G (1999) Chylomicron metabolism in an animal model for hyperlipoproteinemia type I. Journal of Lipid Research 40, 1336-1346.

Schaffner CP, Brill DR, Singhal AK, Bonner DP, Goldstein NI \& Wang GM (1981) Absence of cholesterolgenesis regulation 
in the liver and prostrate of the BIO 87.20 hamster. Lipids 16, $835-840$.

Schoonjans K, Gelman L, Haby C, Briggs M \& Auwerx J (2000) Induction of LPL gene expression by sterols is mediated by a sterol regulatory element and is independent of the presence of multiple E boxes. Journal of Molecular Biology 304, $323-334$.

Semenkovich CE, Coleman T \& Daugherty A (1998) Effects of heterozygous lipoprotein lipase deficiency on diet-induced atherosclerosis in mice. Journal of Lipid Research 39, 1141-1151.

Sessions VA \& Salter AM (1994) The effects of different dietary fats and cholesterol on serum lipoprotein concentrations in hamsters. Biochimica et Biophysica Acta 1211, 207-214.

Shimano HJ, Horton JD, Hammer RE, Shimomura I, Brown MS \& Goldstein JL (1996) Over-production of cholesterol and fatty acids causes massive liver enlargement in transgenic mice expressing truncated SREBP-1a. Journal of Clinical Investigation 98, 1575-1584.

Shimano HJ, Horton JD, Shimomura I, Hammer RE, Brown MS \& Goldstein JL (1997) Isoform 1c of sterol regulatory element binding protein is less active than isoform 1a in livers of transgenic mice and in cultured cells. Journal of Clinical Investigation 99, 1161-1169.

Singhal AK, Ayengar NKN, May PS \& McSherry CK (1983) Cholesterol metabolism in two strains of hamster. In Dietary
Fats and Health, pp. 267-277 [EG Perkins and WJ Visek, editors]. Champaign, IL: American Oil Chemists' Society.

Trautwein EA, Liang J \& Hayes KC (1993) Cholesterol gallstone induction in hamsters reflects strain differences in plasma lipoproteins and bile acid profiles. Lipids 28, 305-312.

Xu R, Yokoyama WH, Irving D, Rein D, Walzem RL \& German JB (1998) Effect of dietary catechin and vitamin E on aortic fatty streak accumulation in hypercholesterolemic hamsters. Atherosclerosis 137, 29-36.

Yagyu H, Ishibashi S, Chen Z, Osuga J, Okazaki M, Perrey S, Kitamine T, Shimanda M, Ohashi K, Harada K, Shionoira F, Yahagi N, Gotoda T, Yazaki Y \& Yamada N (1999) Overexpressed lipoprotein lipase protects against atherosclerosis in apolipoprotein E knockout mice. Journal of Lipid Research 40, 1677-1685.

Yang W-S \& Deeb SS (1998) Sp1 and Sp3 transactivate the human lipoprotein lipase gene promoter through binding to a CT element: synergy with the sterol regulatory element binding protein and reduced transactivation of a naturally occurring promoter variant. Journal of Lipid Research 39, 2054-2064.

Zhang Y, Repa JJ, Gauthier K \& Mangelsdorf DJ (2001) Regulation of lipoprotein lipase by the oxysterol receptors, LXR alpha and LXR beta. Journal of Biological Chemistry 276, 43018-43024. 